\title{
Multipass Performance of Different Medias in Aircraft Hydraulic Filters
}

\author{
B. Aruljothi* and A. M. Junaid Basha \\ Combat Vehicles Research and Development Establishment, Avadi, Chennai-54, Tamil Nadu, India; \\ aruljothicvrde@gmail.com, junaidbashaam@yahoo.com
}

\begin{abstract}
The aircraft filters have to be designed to cater for high reliability and stringent environmental conditions. The performance of filter is decided based on the filter media and its rating. Filter rating is evaluated using multi pass test under constant flow conditions. Generally there are two types of medias used in development of aircraft hydraulic filters (I)glass fibre media and (II)stainless steel mesh media. Glass fiber media is consided as absolute rated and possess high filtration efficiency compared to the stainless steel mesh media. Stainless steel mesh media filters are of non disposable in nature and possess nominal filter rating. The present paper describes the comparitive study of two filter medias and evaluation of filter rating using multi pass test.
\end{abstract}

Keywords: Glass Fibre Media, Number of Particles, Pressure Drop, Rating, Stainless Steel Mesh Media

\section{Introduction}

The Aircrafts are designed to operate at high altitude conditions during maneuvering ${ }^{1}$. The performance aircraft depends on the control surfaces actuated by the system. Filters used in the hydraulic system improve the performance by controlling contamination of oil ${ }^{2}$.

The most common measure of filter performance is $\beta$ ratio, which addresses how efficiently a filter removes particles from the fluid. Few consider a filter characteristic known as retention efficiency, which measure how effectively that filter holds onto particles it has previously captured under the stresses of a hydraulic system ${ }^{3}$.

The efficiency of filtration and the cleanliness of fluid are essential factors, which affect the reliability and service life of fluid power systems. Field studies have shown clearly the relation between clean fluid and low failure rate [DTI (1984)] .

The efficiency of hydraulic filters is generally defined in laboratory conditions using the standardized Multi-pass test [ISO 16889 (1999)]. This standard is a revision of the original Multi-pass standard [ISO 4572 (1981)].
Glass fibre media has superior fluid compatibility as compared to stainless steel mesh media with hydraulic fluids, synthetics, solvents, and water-based fluids. Glass fibre media also has significantly better filtration efficiency over stainless steel mesh media even in elements with the same "micron" rating.

The filter rating is decided in a variety of methods that are applied to specify performance of the filter. Pore size ratings refer to the size of a specific particle retained by the filter media to a specific degree of efficiency. Two methods are used to define media ratings (1) nominal and (2) absolute micron rating. The absolute rating of a filter refers to the diameter of the largest spherical glass particle, normally expressed in micrometers $(\mu \mathrm{m})$, which will pass through the filter under laboratory conditions. It represents the pore opening size of the filter medium. The nominal rating refers to a filter capable of cutting off a nominated minimum percentage by weight of solid particles of a specific contaminant greater than a stated micron size, normally expressed in micrometers $(\mu \mathrm{m})$. It also represents a nominal efficiency nothing but the degree of Filtration. Filter media is main factor

${ }^{*}$ Author for correspondence 
deciding the pressure drop across the filter. The filter should possess low friction and high flowing media. The glass fibre media filters are used where absolute filtration is required for operating precision hydraulic control valves. Whereas the stainless steel mesh medias are used for nominal filtration required for operating hydraulic pumps, motors and direction control valves ${ }^{6}$. The filters are subjected to severe differential pressures at extreme cold conditions due to increase in oil viscosity. Hence the aircraft hydraulic filters have to be carefully designed with proper support to the filter media to withstand the severe differential pressures. The filter designer has to compromise between the major factors like dirt holding capacity, minimum initial clean filter element pressure drop and media support to withstand the high differential collapse pressure ${ }^{7}$. The sophisticated filters used in the aircraft hydraulic systems normally operate with filtration rating ranging from 3 to 30 microns. The aircraft filters have to be designed to cater for high reliability and stringent environmental conditions as per International standards conforming to MIL- F-8815E .

The present work describes the evaluation of rating of aircraft hydraulic filters with glass fibre and stainless steel mesh medias using multipass test facility. The comparative test results are presented and the conclusions are drawn.

\section{Construction of Fibre Glass and Stainless Steel Mesh Media}

Normally the glass fibre and stainless steel media types of filters are used in the hydraulic systems of a combat aircraft. The glass fibre filters are used for absolute filtration of finer contaminations required for operating precision control servo valves and actuators. The stainless steel mesh filters are used for nominal filtration of contaminants for less precision hydraulic valves, pumps and motors. The construction of a glass fibre filter involves a central perforated stainless steel tube wound over with pleated glass fibre media of requisite filter rating along with supporting rayon fabric and course stainless steel mesh. Construction of glass fibre media is shown in Figure 1. The pleated media structure is glued at both ends with end caps as shown in Figure 2. In the case of stainless steel mesh filters, the stainless steel media of requisite filter rating is supported with course stainless steel mesh pleated and wound over a perforated central steel tube. The pleated structure is

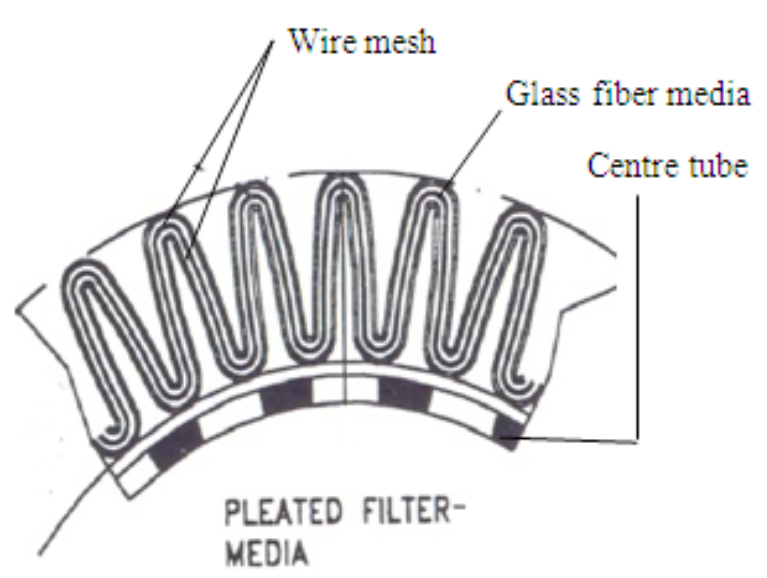

Figure 1. Construction of glass media Filter element.

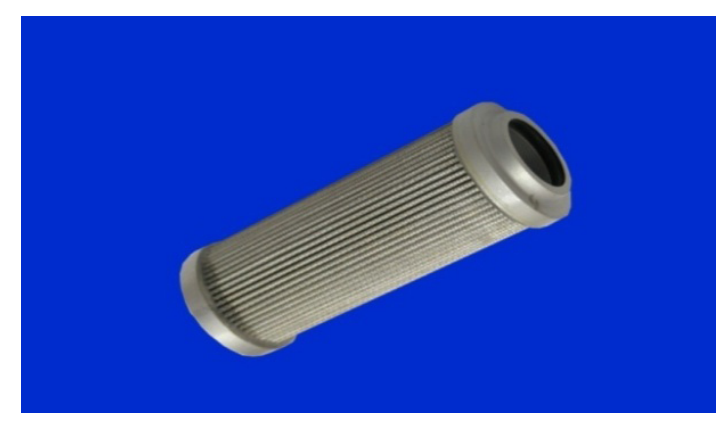

Figure 2. Glass fibre filter.

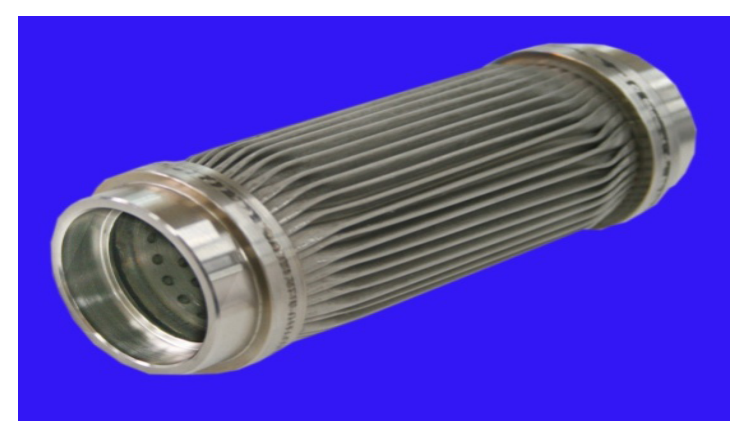

Figure 3. Stainless steel mesh filter.

Table 1. Specifications of selected filters

\begin{tabular}{ccccl}
\hline Sl No & $\begin{array}{l}\text { Filter rating, } \\
\text { micron }\end{array}$ & $\begin{array}{l}\text { Flow, } \\
\text { lpm }\end{array}$ & $\begin{array}{l}\text { Pressure, } \\
\text { bar }\end{array}$ & $\begin{array}{l}\text { Filter } \\
\text { media }\end{array}$ \\
\hline 1 & 10 & 20 & 10 & glass fibre \\
2 & 12 & 40 & 3.5 & $\begin{array}{l}\text { stainless } \\
\text { steel mesh }\end{array}$ \\
\hline
\end{tabular}


welded with end caps at both ends as shown in Figure 3. While designing the filters, care is taken to maintain the clean element pressure drop to the minimum at the same time provide proper support to the filter media against collapse pressures during cold start and clogging build up pressures.

For the present work two different rating glass fibre and stainless steel mesh filters have been selected as shown in Table 1. The two filters are subjected to multipass test and rating of glass fibre and stainless steel mesh filters are evaluated and compared. The multipass test and evaluation of filter rating are described in the following

\section{Multipass Test}

In this test, calculated amount of dust is added to the oil and allowed to pass through the filter. This test is done to calculate the efficiency of the filter. The contaminated oil is circulated through the filter to achieve the filtration to the required rating 9 .

\subsection{Multipass Test Set-up}

The layout of Multi-pass test rig with contamination injection system is shown in Figure 4 and Multi-pass test facility is shown in Figure 5. It is a versatile test rig used for conducting filtration test for the filters and mainly to evaluate the $\beta$ ratio and the filtration efficiency of the filters as per MIL-F-8815E standards. Although hydraulic systems experience cyclic flows during operations leading to lower filter performance, in the absence of standard procedures, most of the filter manufacturers utilize the multi-pass test at steady flow rates. The multi-pass test rig is also used for testing bypass valve operation for checking out cracking pressure and the

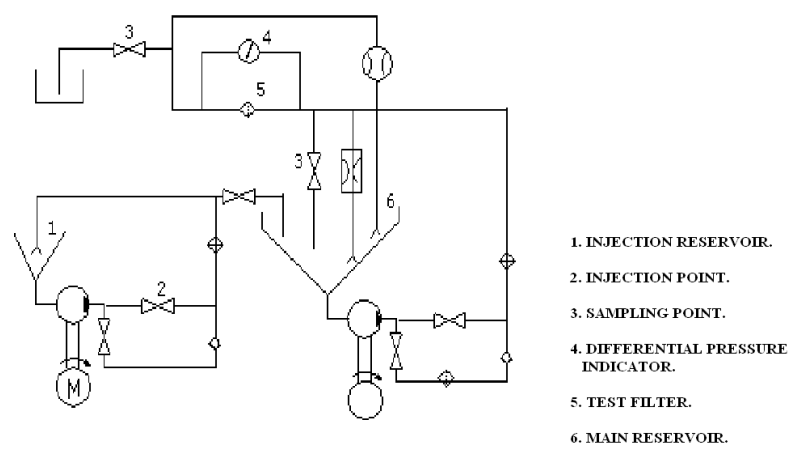

Figure 4. Layout of Multi-pass test rig with combination of injection system.

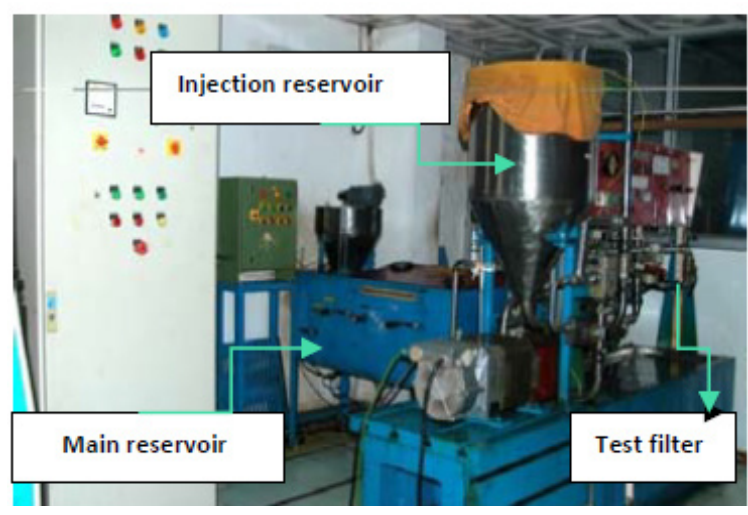

Figure 5. Multi pass test set up.

leakage through the valve. Differential Pressure Indicator (DPI) operation of all the filter assemblies can be tested in this test rig. This can also be used for determining clean element and housing pressure drop across the filter assemblies.

\subsection{Test Conditions}

Test fluid

: MIL-H-5606

Cleanliness level required

: NAS class 4

Temperature

: $30^{\circ} \mathrm{C}$

\subsection{Dust Addition}

Table 2. Dust addition details

\begin{tabular}{ll}
\hline Dust name & $\begin{array}{l}\text { ACFTD (Air Cleaner } \\
\text { Fine Test Dust) }\end{array}$ \\
\hline Cleanliness of oil & $\begin{array}{l}\text { NASCLASS 2-4 (Before } \\
\text { addition of dust) }\end{array}$ \\
Capacity of impurity & $200 \mathrm{mg} /$ lit \\
Injection tank capacity & $25 \mathrm{lit}$ \\
Flow & $40 \mathrm{lpm}$ \\
Test dust added & ACFTD $(5 \mathrm{mg} / \mathrm{lit})$ \\
\hline
\end{tabular}

\subsection{Test Procedure}

A calculated amount of dust is added to the oil and stirred for 15 minutes. Then it is allowed to pass through the filter. Due to the presence of dust particles, pressure development occurs across the filter. The oil sample is collected in a clean bottle both at inlet and outlet for a particular rise in pressure. All the parameters are recorded in the multi-pass test sheet. This process is repeated for various levels of pressure drop. Then the oil samples are tested in 
the particle counter apparatus shown in Figure 6. Then the beta ratio is calculated to obtain the efficiency of the filter. The filter rating $(\beta)$ is given by

$$
\beta_{\mathrm{X}}=\frac{\text { No. of particles }>x \text { micron size in upstream }}{\text { No. of particles }>x \text { micron size in downstream }}
$$

and the filter efficiency is given by

Filter efficiency $=\frac{\beta_{\mathrm{x}^{-1}}}{\beta_{\mathrm{X}}} \times 100$

\subsection{Filter Rating Characteristics of Two Medias}

The filter performance $\beta$ ratio obtained from the test samples plotted for the glass fibre and stainless steel media filter are shown in Figures 7 and 8.

\section{Results and Discussion}

From Figure 7 it is observed that Type 1 filter with $10 \mu$ filter element using glass fibre media element possess $\beta$ ratio of 125 at the differential pressure of 1.5 bar and 180 at the differential pressure of 4 bar. This infers glass fibre media has more dirt holding capacity at higher pressure drop. This indicates higher filtration efficiency in the case glass fibre media filter at longer service life. From Figure 8 it is observed that Type II. Filter with $12 \mu$ filter element using stainless steel media as element possess $\beta$ ratio of 17 at the differential pressure of 1.5 and 15 at the differential pressure of 3.5 bar. The stainless steel media filter performance shows that up to $10 \mu$ particle size the $\beta$ ratio is higher for the differential pressure of 3.5 compared to 1.5 bar differential pressure. Whereas

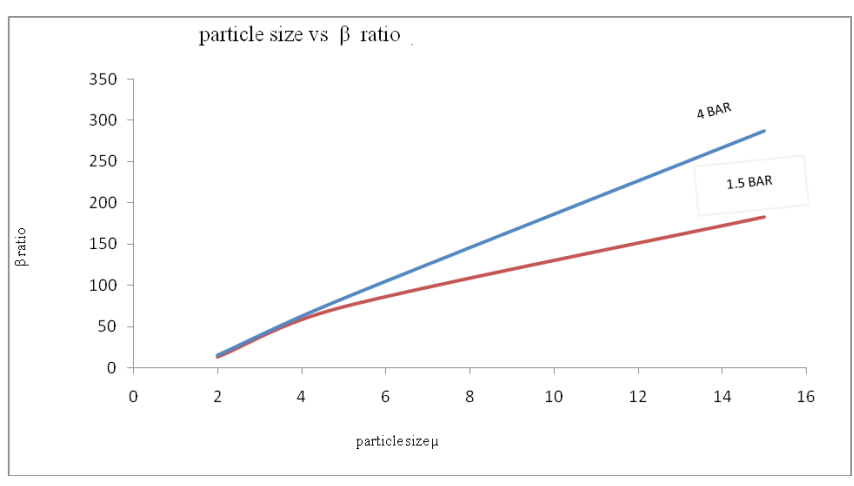

Figure 7. Performance of glass fibre media. for particle size higher than $10 \mu$ the $\beta$ ratio is lower at higher differential pressure across the filter element. This reveals that longer service life of filter, the efficiency of a stainless steel mesh filter will be less compared at the initial operations. Hence for the longer service life and higher $\beta$ ratios and efficiency the glass fibre media filters are useful. Therefore for Aircraft engines and control surface hydraulic systems the glass media filters are used ${ }^{10}$.

\section{Conclusion}

The filter rating is an important parameter for determining the filter performance. Glass fibre and stainless steel medias are generally used for aircraft hydraulic systems. A glass fibre $10 \mu$ filter multipass pass test is compared with a $12 \mu$ stainless steel media for filter rating performance. The glass fibre filter shows $125 \beta$ ratio at 1.5 differential pressures compared to stainless steel media filter $\beta$ ratio 17. The effective $\beta$ ratio increases from 125 to 180 for a 1.5 bar differential pressure to 4 bar differential pressure.

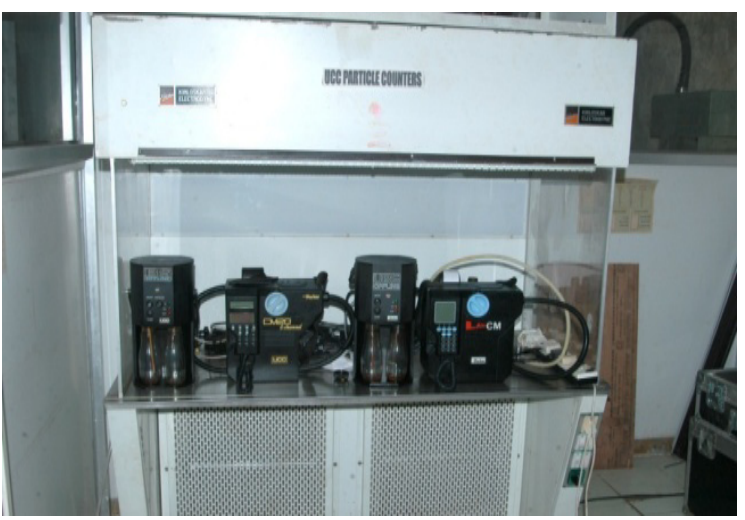

Figure 6. UCC particle counter.

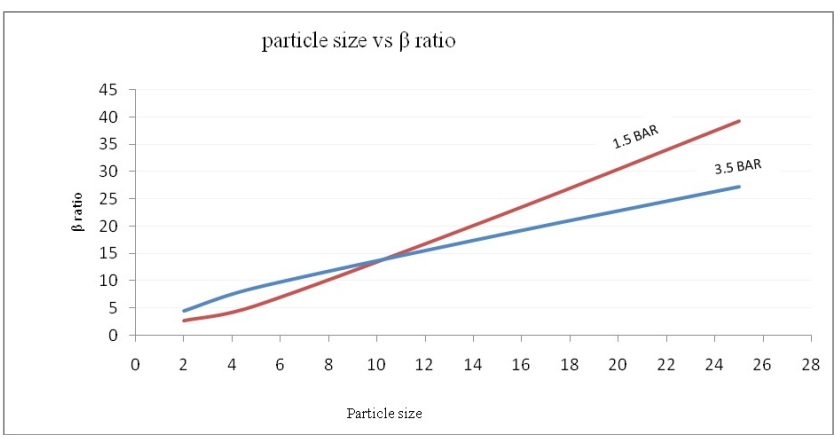

Figure 8. Performance of stainless steel media filter. 
This is ensuring higher efficiency of the glass fibre media in long operational life whereas the $\beta$ ratio reduces from 17 to 15 for stainless steel mesh media for increasing differential pressure of $1.5 \mathrm{bar}$ to $3.5 \mathrm{bar}$. This indicates the efficiency of the stainless steel mesh filter will reduce in the long service life. Therefore higher dust holding capacities as well as higher efficiency retainement in a longer service life of a hydraulic filter for aircraft applications; glass fibre medias are more effective and efficient. The final 10 $\mu$ glass fibre filter offers higher pressure drop losses due to more flow resistance in filter media. Therefore the sizing of the finer glass fibre filters has to be carefully designed to ensure sufficient pressure in the system beyond filters for efficient operation of hydraulic actuators.

\section{References}

1. Herbst WB. Future fighter technologies. J Aircraft. 1980 Aug; 17(8):561-566.

2. Sutherland K. Filters and filtration handbook. UK: Elsevier Publications; 2008.

3. Hoeg A. Hy-Pro Filtration Fishers, Ind. Available from: www.filterelement.com

4. DTI. Contamination control in fluid power systems. vol 1, Field Studies, Department of Trade and Industry, East Kilbride, Glasgow, UK, 57, 53; 1984.
5. ISO 4572. Hydraulic fluid power- Filters - Multi-Pass method for evaluating filtration performance, ISO. 28 p; 1981.

6. MIL-H-5440C-Class 3000. Hydraulic components, aircraft and missile general specifications for $65^{\circ} \mathrm{F}$ to $+275^{\circ} \mathrm{F}$ fluid temperature range filter and filter element suitable for operating pressure up to and including 3,000 psi. Available from: www.everyspec.com

7. Aruljothi B, Basha AMJ. Design criteria for aircraft hydraulic filter. Frontiers in Automobile and Mechanical Engineering (FAME). 2010 Nov 25-27, Chennai. IEEE. p. 291-94.

8. MIL -F-8815E - Filter and filter Elements, fluid pressure, hydraulic line, and $15 \mu$ absolute, and $5 \mu$ absolute, Type II systems - General specification for Supplement; Sep 1, 27 1976. Available from: www.everyspec.com

9. ARP 598- Procedure for the determination of particulate contamination of hydraulic fluids by the particle count method. Society of automotive engineers, 400 common wealth Drive, warren dale, PA.1. Available from: www. everyspec.com

10. Jothi BA, Basha AMJ. Development of a hydraulic filter for nozzle actuation system of a gas turbine engine. Proceeding of ASME 2012 Gas Turbine India Conference, GTIndia2012; Dec 2012; Mumbai. ASME Proceedings. p. 717-23. 